\title{
12. Hidden for Sixty Years: The motion pictures of the American-Australian Scientific Expedition to Arnhem Land
}

\author{
Joshua Harris
}

\section{Introduction}

Fellow Members and Guests of the National Geographic Society: It is a great pleasure to give you a report on the Arnhem Land Expedition. 'Aboriginal Australia' represents a film originally three miles long, condensed to a mere three thousand feet. ${ }^{1}$

\section{— Frank Setzler}

These words, spoken by Frank M. Setzler, opened his lecture and report on the Arnhem Land Expedition at Constitution Hall in Washington, DC, on Friday evening, 13 January 1950. The lecture's centrepiece were the sights and sounds recorded during 10 months in the field - a meticulously edited film taken from hours of raw footage shot by photographer Howell Walker as the representative of the National Geographic Society (NGS).

In early 2007, all that was known to us in the National Geographic Society Film Archives was the existence of the 'mere three thousand feet' of film from Setzler's lecture (roughly 75 minutes of footage). The extent of the archival materials relating to the moving images shot by Walker was the two original reels of the lecture film 'Project 73 Aboriginal Australia' and some scant notes in a slim file relating to it.

When contacted by Martin Thomas in early 2007, nothing was known about the whereabouts of any of the original raw footage captured by Walker (the 'three miles' Setzler mentions). It was certainly a possibility that additional footage existed, but locating and identifying such film would be a monumental task. Expedition films of this type were often passed around at will, cut, edited, reedited and lost with little regard for their historical significance. Many times the 'outtakes' (footage not used in a final production) were discarded and considered 'useless' once the edited piece was finished. In addition, the cataloguing of film reels and footage was often non-existent, or so poor that no information could be garnered without intensive investigation. In many instances, even something

1 Transcription of introduction to speech of Frank Setzler given at Constitution Hall, Washington, DC, 13 January 1950, National Geographic Society Film Archives file 'Project 73 Aboriginal Australia', National Geographic Society, Washington, DC. 
as simple as the labelling on the film can or the leader (the first several feet of a film reel, generally used to assist in the threading of film onto a projector or machine, but also used to label visual and audio information) of the film itself was absent, illegible or faded.

Supporting documentation was also slim, making any clues as to the footage's existence difficult. This is evidenced by the very slender file found in a 'lecture films' file cabinet kept in the archive. As was the case with the Arnhem Land project, the file contained very little information. The only real clue in the file, beyond Setzler's quote, which was contained in the file as a photocopy of only the first page of his speech, was a motion picture footage log. (Of unknown date, but most likely from soon after the Expedition, the log indicated that there was a total of seven cans of 'trims'. The term 'trims' was often used in the past to refer to footage cut out of its original camera roll and that was not part of a final motion picture - referred to elsewhere in this chapter as 'outtakes' or 'raw footage'.) This information certainly did not contribute much to the search effort, as it was already obvious from the practice of cinematography itself that Walker would have shot many hours of footage while in the field.

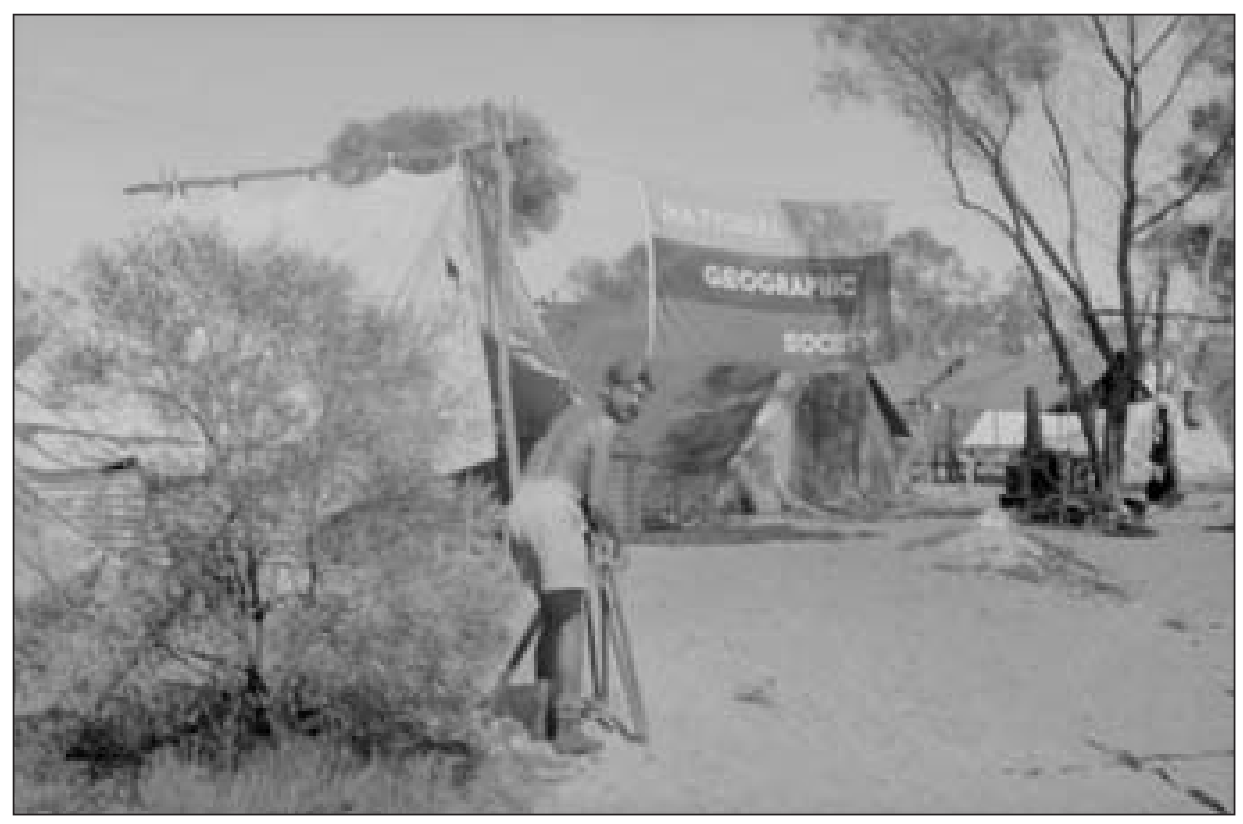

Figure 12.1 Howell Walker using his $16 \mathrm{~mm}$ camera at Umbakumba on Groote Eylandt, 1949

Photograph by Frank Setzler. By permission of National Anthropological Archives, Smithsonian Institution. Photo Lot 36, Box 7. 
The NGS Film Archives consist of hundreds of thousands of elements of film, videotape, audio recordings, paper materials, photographs, artwork and other materials documenting society projects. A large collection holds the visual and audio portions of lecture and research reports given to NGS membership before the introduction of society documentary television production in 1965. Often these lectures were presented as silent films to which the narration was given by a scientist, researcher, journalist or photographer from an expedition. By the time of the talk on the Arnhem Land Expedition, society lectures were immensely popular public events given to large audiences at well-known venues. The Setzler lecture, delivered alongside Howell Walker's film footage at Constitution Hall - a venue of 3700 seats - is therefore the quintessential example of the society lecture film.

Contained within two on-site and three off-site storage vaults, the NGS film collections represent a vast array of film, video and audio formats and a wide range of preservation conditions. Following a theoretical model based upon 'preventative conservation', archive staff work to maintain and monitor optimal storage conditions that will ultimately preserve collections for extended periods, reducing the need for future intrusive conservation of individual items. Storing film in a cool, dry climate increases the life of the collections while also preventing and slowing the further deterioration of already damaged assets. ${ }^{2}$

The history of the film and audiovisual collections at the NGS is not unlike that of many other institutions housing similar materials. Film and video have generally not been well accepted as primary sources and historical documents, and thus the priority given to their preservation has been much lower than that of other collection types. The difficulty, expense and time-consuming processes involved in working with film have placed its preservation well behind that of other contemporary mediums of documentation, especially photographic collections.

\section{Setting the Scene}

The NGS film and audiovisual archives in its current state primarily serves the needs of the NGS television and documentary production departments as well as those of web-based production and stock-footage sales. Thus, the preservation, migration and usage of materials in the collections are determined by demand and their importance to the most current society ventures. In other words, in order for any type of reformatting, migration or preservation action to be undertaken or funded there must be an NGS documentary, new product or outside paying

2 Reilly, J. M. 1993, IPI Storage Guide for Acetate Film, Image Permanence Institute, Rochester, NY. 
client with specific needs for the archival footage. These business decisions are the guiding force behind the priorities placed on collection management and the resources of the staff entrusted with caring for the archives. The consequence of this type of collection management is that many historically significant films are left behind, as well as those that might be more severely degraded or are in need of more intensive conservation actions. This 'on-demand' approach to media migration does not diminish the amount of preservation that has been accomplished and completed; by default, this method, given the age and subject matter held in the collection, does yield some positive results. While certain collections might be heavily utilised for their commercial and aesthetic value to the modern-day filmmaker or producer (the focus is often on more modern footage, often shot with the latest 'hi-definition' cameras or more easily reformatted for modern hi-definition broadcasting standards), other collections remain unknown and hidden far from sight.

Within this context, it is apparent how the possibility of locating any of the additional raw footage from Walker's camera seemed extremely slim. Not only was the film's physical existence in question, but also the resources - both human and otherwise - to put towards such an endeavour were not available. It should be pointed out, too, that the Arnhem Land Expedition films were not the first - and certainly will not be the last - about which queries as to their whereabouts have been sent to the archives. The material was put on the list along with a slew of other questionable, lost, orphaned or otherwise unknown films. An 'orphan work' is a broad term used to describe films that have no clear copyright holder, no commercial potential to pay for preservation or have in some way been neglected. ${ }^{3}$ Historical, ethnographic and documentary film elements are some of the clearest examples of orphaned works: they have often been neglected, lack the background documentation to put them into context and are of unknown copyright or origin.

\section{The Finding}

The location of the Arnhem Land Expedition films was not a methodical or organised venture; rather, it was by chance and only through the search for other, more pressing assets that, one by one, the films began to emerge from hiding. Over the next year a total of 10 individual rolls of film were located in a variety of locations, both at the society's Washington, DC, headquarters and buried in boxes in the off-site storage locations. It was certainly the finding of the first can (containing two rolls labelled \#5 and \#6) in the basement cold vault

3 More information on orphan films can be found online at Duke University: <http://www.law.duke. edu/cspd/pdf/cspdorphanfilm.pdf $>$ (viewed 28 October 2010); and the Library of Congress, National Film Preservation Board: <http://www.loc.gov/film/study.html> (viewed 28 October 2010). 
in Washington that gave the hope that an entire set might be assembled. On trips to the off-site vaults outside Pittsburgh, Pennsylvania, other rolls slowly came to light. A simple look at the dusty cans with their faded labels made it probable that the footage contained within had been viewed or handled by only a few people since the Expedition.

A common practice in filmmaking is to assemble all of the 'camera rolls' of film taken in the field (often about $122 \mathrm{~m}$ each) onto larger reels of about 300-460 m. Therefore, the location of 10 reels (not including the two rolls of edited lecture films) could easily account for all the field footage shot by Walker. It is also probable that camera rolls were discarded before or shortly after processingdeemed by Walker to be of inferior quality or containing footage not worthy or possible of making it into the final lecture film or any other future edited piece.

The discovery of these films was a feat in and of itself. These were truly the 'needle in the haystack'; simply knowing the films existed, were identified and were being held in the proper storage conditions makes this a success story outright. The fact that the films had been kept in cool and dry storage conditions meant that some amount of 'preventive conservation' had been unknowingly taking place. 'Preventive conservation' is a term used by the museum and archive community to refer to storing and housing artefacts within the most optimal environmental conditions to prevent their further deterioration or the need for more intrusive techniques that involve physical handling of the item. ${ }^{4}$

We knew from the notes on file that Howell Walker used Kodachrome film stock in the field. Kodachrome was the most common film stock used by NGS cinematographers at the time. More specifically, the stock was Kodachrome Color Reversal, a film type by which a positive image is produced upon a transparent base. This became a very popular type of film in documentary and ethnographic filmmaking, as reversal film was cheaper and negated the need to process a negative to create a positive film print. The reversal film could be - and very often was - directly projected without need for processing. This certainly is proven by the number of times Setzler and others projected the final lecture film, which was made up of the camera originals. A footage projection log found in the film archive file indicates the final edited film was shown at least 28 timesincluding at universities, museums, conventions and other locales-over a fiveyear period. ${ }^{5}$ Kodachrome itself is well known for its long-term colour accuracy and dark-storage longevity, which make it a very good archival film format in terms of the images themselves. ${ }^{6}$

4 More information specifically related to preventive conservation in film can be found at the Library of Congress, National Film Preservation Board: <http://www.loc.gov/film/storage.html> (viewed 28 October 2010).

5 Film archive file P73 Aboriginal Australia, Screening Footage Log.

6 National Film Preservation Foundation 2004, The Film Preservation Guide: The basics for archives, libraries, and museums, National Film Preservation Foundation, San Francisco, p. 11 
In order to determine if the films were in a state of extreme degradation and might need 'emergency triage', we had to first complete a simple visual inspection. At a minimum, this would add some amount of basic knowledge to our data on the film condition. Even if nothing could be done in the short term, any knowledge would add to our understanding of the collection.

One of the first signs of film decay is the pungent odour of vinegar emanating from the film can or box. 'Vinegar syndrome' is frequently encountered in films from the era in which the Arnhem Land Expedition films were shot, as it is a condition that primarily affects film stock made with a cellulose triacetate base; its progression is greatly affected by storage conditions. The symptoms of vinegar syndrome are the odour, followed eventually by shrinkage, embrittlement and buckling of the gelatin emulsion. Storage in warm and humid conditions greatly accelerates the syndrome's onset; once it begins in earnest, the remaining life of the film is short because the decay process speeds up as it goes along. Early diagnosis and cool, dry storage are the most effective defences. As vinegar syndrome can spread to nearby films, it is also necessary to segregate affected films from better-preserved assets.

Vinegar syndrome is not always easily observed by the sense of smell, as trace amounts might be undetectable to human senses. The film archivist can use certain tools to measure the amount of free acid in the film can. In the case of the Arnhem Land films, there was no noticeable odour upon opening the containers, and no visible damage was apparent. The Image Permanence Institute at the Rochester Institute of Technology has developed a product called A-D strips, which are used to measure the amount of free acid present in film containers. These strips change colour when exposed to acetic acid and are a very useful tool in determining the level of film deterioration. ${ }^{7}$ A-D strips were immediately placed into the film cans in order to measure the true amount of acetate degradation occurring.

The films did appear to display common signs of age, such as warping and possibly some shrinkage. Over time a certain degree of shrinkage occurs due to the evaporation of solvents and other agents left over from the manufacture of the film base as well as decomposition reactions in the base. ${ }^{8}$

We also noticed that the rolls contained an extremely high number of 'splices'. Small pieces of film are joined together to form longer, continuous rolls, and splicing was a key technique used in film cutting and editing. A variety of materials have been employed in the past to join pieces of film together and create these 'splices'. During much of the twentieth century, various types of

7 Image Permanence Institute 1998, User's Guide for A-D Strips, Image Permanence Institute, Rochester, New York.

8 Ibid., pp. 12-15. 
glues, adhesives, tapes and cements were used. Such materials can cause myriad problems when it comes to film degradation. Not only can splices become brittle and break apart, the adhesives can ooze onto images or remain stuck after tape is removed. Splices as crude as masking tapes, electrical tape or transparent 'office' tape have been observed in the NGS collections. These crude splices are seen primarily in films from the documentary genre, as opposed to those from 'Hollywood'-style narrative films, and are usually indicative of time constraints and budgetary concerns.

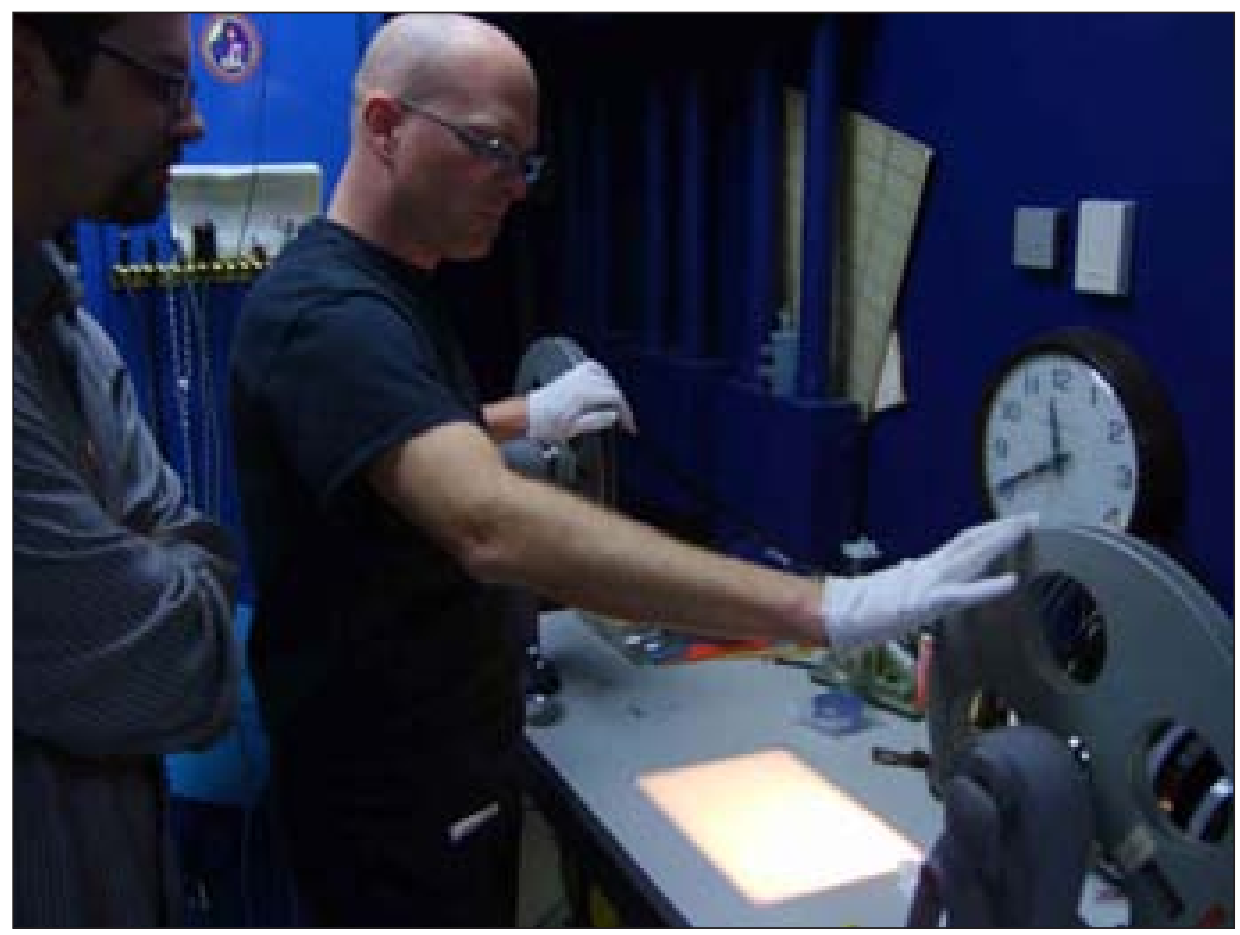

Figure 12.2 Archivists Joshua Harris and Bryce Lowe examine a reel of outtakes from the Arnhem Land Expedition films, 2008

Photograph by Martin Thomas

Thus, we knew shortly after their discovery and through the use of A-D strips and the bare minimum visual inspection that the films did exhibit some expected signs of age but were considered to be overall in 'fair' condition. Since no immediate action could take place, simply knowing of the films' existence, having the assets inventoried and placed in a 'known' location in the vault, and creating catalogue records in a database, were about as much as could be expected. 


\section{The Examination}

As new formats emerge within broadcasting and technologies evolve, the human resources of a television archive are also shifted in that direction. As budgets tighten and production schedules become shorter, the time is not available for an archivist with limited resources to spend days scrolling through footage or meticulously repairing splices and damaged film. This is evidenced by the remarkable fact that National Geographic Television sold, gave away or discarded all of its traditional film editing, repair and viewing equipment more than 10 years ago to follow the swift-moving wave into digital video production. The only film bench left is in a cramped corner of the often-crowded projection booth of the Grosvenor Auditorium at the society headquarters in Washington, DC.

This situation made a full conservation effort of the Arnhem Land Expedition films fairly unlikely. As manager, I was unable to spare even a few precious man-hours for an archive staff member to examine the films in more detail. But, as we squeezed in time at night or on the weekend, we were able to at least do a cursory examination of the films and get a general idea of their condition. On initial examination, we were delighted that the film images themselves appeared to be excellent. Colour fading is one of the most noticeable and fastacting chemical processes occurring in film over time. Films often take on a purple hue, due to the fading of less stable yellow and cyan dyes that make up colour images. The situation with the splices, though, was even worse than had at first been thought. The films in the Arnhem Land collection appeared to have been assembled hastily and with little regard to future usage. A variety of tapes not designed for film splicing were utilised, including masking tape and pieces of paper with glue applied to the surface. In several instances, film was joined together with overlapping images - that is, frames from one reel placed directly on top of frames from the next reel. We also noticed that there was no continuity within the outtakes and the films were assembled with disregard to subject matter or time line. For example, shots of Setzler examining artefacts were spliced to footage of Arnhem Landers fishing into which were interjected eight frames of unrelated scenes of ceremonial footage. A few glaring examples of the lack of care taken with the outtakes are shown by the fact that there are several sequences of 'flipped images', where a piece of film is spliced upside down to its adjoining piece. When displayed, this would show the clip upside down-evidence once again of the fact that little regard was placed on the raw field footage as a legitimate historical artefact or an asset that would be utilised in the future. Several other types of damage included warping, curling, emulsion scratches (which create visible blemishes on the image) and broken sprocket transport holes. 
Some of the problems, such as shrinkage and colour fading, are irreversible. Modern technological advancements in digital film restoration provide some hope for addressing these issues, but it was clear that the film originals had undergone permanent damage. Other damage, such as splices and perforation breaks, can be repaired but only with a significant amount of meticulous time and effort. These film degradation issues are of concern because they also make the process of transferring the films to modern media problematic. Any type of film transfer or migration requires running the film through often complex and complicated equipment. A minimal amount of repair and preparation has ideally to be accomplished in order to run the film through modern film equipment without risking further damage to the original.

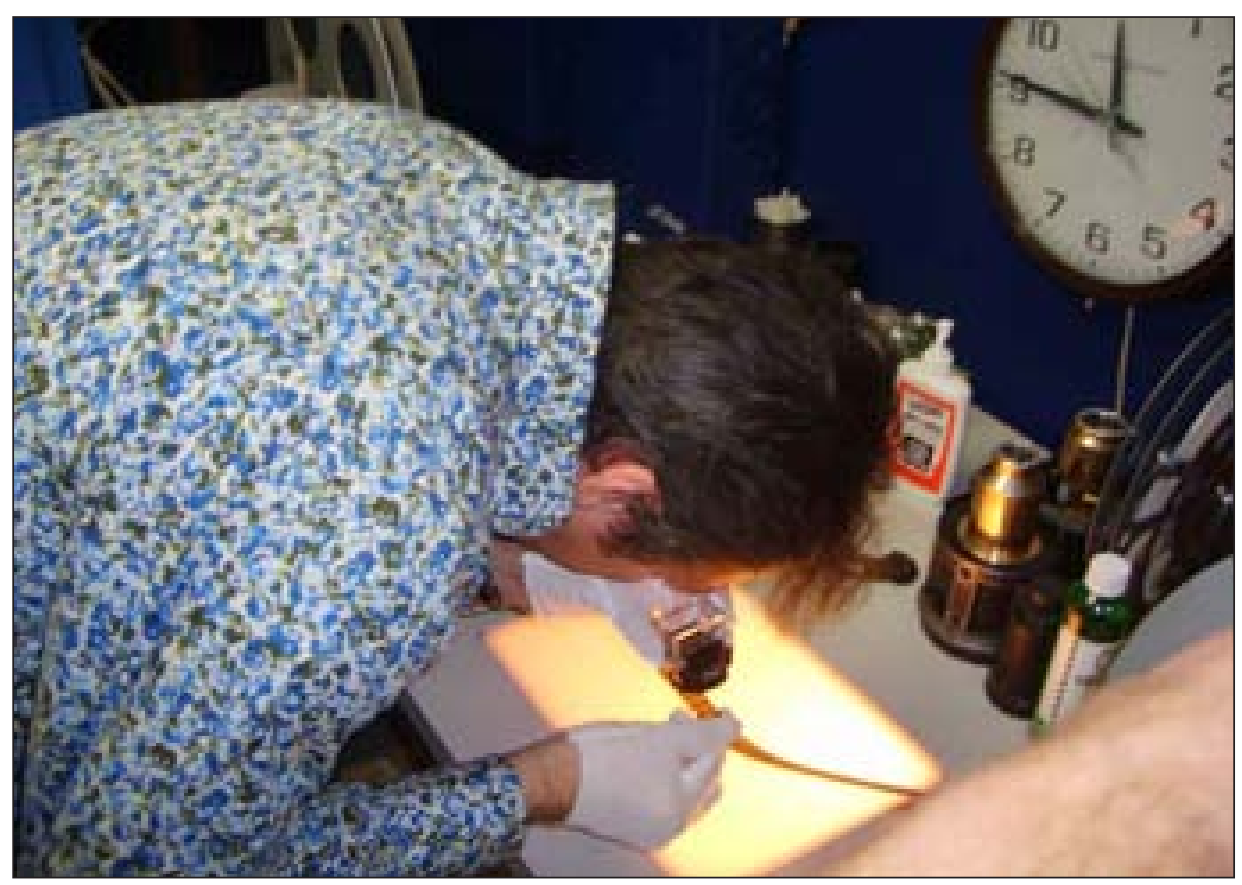

Figure 12.3 Historian Martin Thomas taking a close look at some footage frames from the Arnhem Land film collection, 2008

Photograph by Josh Harris

Thus, reel by reel, we managed to get a little better idea as to the true condition of the reels. These types of metadata are very important and were added to the catalogue records for these assets. If no immediate work could be done on the films, it was very important for us as archivists to capture whatever information we could (whenever we could!) to aid in future possible use, preservation or restoration efforts. Just knowing this type of information makes the process of applying for funding or preparing future proposals much easier. The more that is known about the asset's condition, the more precise is a price estimate that can be put together for a more intensive preservation project. 
The timing was certainly right for the discovery of this 'lost footage'. Claims had been made and notices given by myself and several previous NGS archivists as to the number of historically significant films in the collections that needed some type of attention. The sheer volume of pre-1965 films that have never been transferred to a newer medium is staggering. But this is by no means a rare or unusual case within moving-image collections, and claims for preservation dollars typically become a yearly routine for most film archivists. The archivist finds him or herself fighting a constant battle against time and rapid technological changes while attempting to prevent the further decay of the artefact. The NGS is no exception to the general rule that the battle for precious dollars will always favour higher priorities, societal operations and more immediate business decisions. Given the recent global economic downturn, this holds true now more than ever.

\section{Saving the Footage}

Mid December 2007, however, brought excellent news with the potential to break this trend of neglecting older films; in fact, it had been more than 10 years since the last preservation project involving pre-1965 films. Some extra fundsnot utilised during the fiscal year-were still available. But the time line was tight; these one-time budgetary items had to be used by the end of the calendar year. A proposal and project plan would have to be written up immediately and the project had to begin by the last day of 2007 in order to be accepted. From an archival perspective, where projects are often planned in the long term and take shape over a fairly lengthy period, this was not ideal, but it might have been our only chance to work on these collections. We wrote a simple yet comprehensive proposal in only a matter of days. To our amazement, the funding was approved, but the stipulations and demands put on the project were considerable: the greatest number of footage hours was to be transferred to the highest-quality format possible with the most minimal amount of physical film preparation and repair. This posed an extremely difficult challenge as we tried to plan and start this project in a matter of two weeks.

The archivists themselves - as the only few people in the society with any knowledge concerning the audiovisual collections - were offered the freedom to choose the majority of the films to be transferred. This was a rare case in an institution with so many conflicting ideas on the priority level given to certain subject matter. The films from 'Project 73' were given highest-level priority, and it was within this framework that the Arnhem Land films found their way into a shipping container destined for Crawford Communications in Atlanta, Georgia (the lab commissioned to assist in carrying out this project). All 10 rolls of outtakes were to be converted, including the two original lecture films, totalling almost 12 hours of footage. 
There is no single, straightforward workflow for the preservation, restoration or migration of moving-image artefacts. Each film roll will have its own situation and will need to be treated as an individual case. A basic framework must be established and laid out with the laboratory, and parameters put on the type and nature of intervention to be taken on each film. There is not enough time to discuss the endless number of possibilities that arise from a project such as this. This is also not the forum to discuss the theory, techniques, criteria and ethical concerns for moving-image migration, duplication or restoration. But it should be noted that film archivists and those charged with caring for audiovisual collections do face an immense number of issues regarding any such project. This holds ever truer as digital technologies continually add to the ways in which images can be manipulated and altered. ${ }^{9}$

As the project came together, it was clear that given the budgetary organisational and time restrictions placed upon us, a true 'restoration' project would not be possible. The goal, in effect, would be 'duplication' - the essential function of creating a facsimile of the films. The facsimile, used for access and preservation purposes, would negate the possibilities of having to touch the original films, thereby preventing further degradation due to physical handling.

We were adamant about maintaining as much of the authenticity of the films as possible. That is, the images would be exact replicas, blemishes and all; they would not be 'colour corrected' and would therefore maintain as much of the visual integrity, such as colour saturation and balance, as Howell Walker had captured. The films would be scanned, frame by frame, at a resolution of $4 \mathrm{k}-$ the highest resolution available at the time. Scanned footage would be output to a high-definition format known as D-5, with other very specific parameters placed upon 'frame rate'. Our guiding principle was to replicate the look and feel of the original film, in its current state. This would create a true historical document that would also show the ageing and decay that occurred to the original over time. No further digital 'touch-up' would occur. Digital tools would be used only to stabilise film that could not run through the scanner due to shrinkage, warping or other damage.

The transfer process was not without its issues and problems. Even with minimal intervention, films as fragile as these took a significant amount of time to duplicate. Most were too delicate to be cleaned properly because some of the chemical solvents used could break apart bad splices or further damage the originals. As the films went through the scanner, several broke in the machine and had to be repaired immediately. Shrunken film had to be slowly scanned and stabilised and the tapes and adhesives removed by hand if affecting the

9 Wallmuller, J. 2007, 'Criteria for the use of digital technology', Moving Image Restoration, vol. 7, no. 1, pp. 1-19. 
transfer. Some of the limitations of technology and the large amounts of storage needed for digital files required some rescanning of the films. It is worthwhile to note here that communication and open dialogue with any lab doing such intensive work are vital. For example, we quickly realised that the technicians had flipped the upside-down images mentioned earlier and had taken other actions not agreed upon. The only way to fix these issues would be to rescan the film - a chance we did not want to take given its physical state. This again shows how professional laboratories - more accustomed to production than archival footage - might not fully understand the archivist's perspective and might be prone to decision making that does not adhere to the unique aspects of working with archival moving images.

The final steps of this story come with the footage returned to the society's headquarters. We placed the films in new archival film cans and accessioned the new film transfer masters, creating new catalogue records in the database. We created additional backup copies including standard-definition (not highdefinition) copies and DVDs to be added to the NGS film library as loan copies. We ended by fully digitising each tape into our 'media asset management' system, creating a full-resolution preservation file, a medium-sized (Mpeg-2) file appropriate in many production settings and a low-resolution, highly compressed file (Mpeg-1), which can be used for Internet online access. While there are still many 'unknowns' in the world of digital moving-image preservation, we were able to utilise some digital tools in order to better preserve the Arnhem Land Expedition films and ensure their accessibility far into the future. We hope that the footage will be made available to a wider audience via the World Wide Web in the near future.

\section{Conclusion}

The discovery and preservation of Howell Walker's films from the 1948 American-Australian Scientific Expedition to Arnhem Land are a modern-day success story in film archiving. Despite the bumps in the road and some lessthan-ideal situations, it is remarkable that the films have survived and have now found a new life, more than 60 years after the Expedition itself. Their survival is proof of the importance of proper storage conditions for film and audiovisual collections, but their discovery and conservation also demonstrate the difficulties and challenges faced by moving-image archives worldwide as they attempt to preserve and provide access to these artefacts. The time, funds and resources to work with these collections make them very difficult and expensive to care for. Knowing the global financial crisis began shortly after this project was finished makes it very clear now just how lucky we were to spend some time preserving this collection. 
Film collections are still only gaining acceptance as important historical documents and artefacts. The work described in this chapter has presented the films of the Arnhem Land Expedition as a real-life example of the legitimate place of moving-image collections as a part of our global cultural heritage. It is clear that the hard work, effort and time-consuming processes needed to migrate and digitally preserve these films will deepen our understanding of the Arnhem Land cultures and the Expedition as a whole. Thus, the legacy of the Expedition will continue and the educational value of the materials it collected will increase long into the future. 